\title{
HEPATIC COMA: THE ELECTROENCEPHALOGRAPHIC PATTERN
}

\author{
By REGINALD G. BICKFORD AND HUGH R. BUTT \\ (From the Section of Physiology and the Section of Medicine, Mayo Clinic and Mayo Founda- \\ tion, 1 Rochester, Minn.)
}

(Submitted for publication June 28, 1954; accepted February 23, 1955)

Recent advances in our knowledge of the neurophysiologic mechanisms underlying sleep and experimental states of coma (1) suggest the need for a neurophysiologic approach to the many complex clinical syndromes associated with disturbance of consciousness. The coma syndrome associated with hepatic disease and usually known as hepatic coma was chosen for investigation since it presents a good example of toxic coma without gross structural change in the brain. The rapid changes in level of consciousness which frequently occur in this syndrome make it particularly susceptible to experimental study.

The observations described below represent an effort to analyze such electroencephalographic (EEG) patterns as may be observed in patients with various forms of hepatic disease before, during, and after the clinical state known as hepatic coma.

\section{MATERIAL AND METHODS}

The patients to be described fall into two categories. The first is a series of 8 patients in whom there was clear evidence of hepatic disease (cirrhosis) which, on a clinical estimate, might be expected to culminate in hepatic coma. At the time of recording, these patients were in a normal mental state. This series of patients formed a control group to evaluate the EEG effect of hepatic disease without coma. The second category consists of a group of 13 patients in whom a state of hepatic coma developed.

Owing to the grave clinical condition of the patients in coma it was felt advisable to make recordings in the patient's room. Conventional solder disc electrodes were used, the placement being that shown in Figure 1, and in the early cases the recordings were made on a specially constructed 4-channel, portable inkwriting electroencephalograph. More recently, recordings have been made on a standard 8-channel, Grass, inkwriting oscillograph. The state of consciousness of the patient was evaluated throughout the recording. The effect of arousal stimuli, such as a loud clap, squeezing of the

1 The Mayo Foundation, Rochester, Minnesota, is a part of the Graduate School of the University of Minnesota. toes and pinprick, were investigated. In most instances, photic stimulation by means of strobatron light $(250,000$ foot candles) was carried out, the light being held 1 foot from the patient's eyes. The patients in the control group underwent a standard EEG recording using a Grass 8-channel instrument. In all instances the mental state of the patient was classified on the basis of the following terms : 1) alert, 2) confused, 3) semicoma, and 4) coma. The semicomatose patients were out of contact with their environment and spoke only a few, usually inappropriate, monosyllables. Comatose patients were those who showed little spontaneous movement and no response to noxious stimuli.

\section{RESULTS}

\section{Control group}

The EEG findings in the group of patients with hepatic disease in the absence of mental changes are shown in Table I. An alpha rhythm was recognizable in all cases and in no instance were the EEG changes considered to be beyond normal limits. A comparison of Tables I and II indicates that the kind of hepatic involvement in the cirrhotic group without mental changes was essentially similar to that found in the group exhibiting coma (Table III). It can be concluded that the existence of hepatic disease per se in the absence of mental change is not associated with any detectable EEG abnormality.

\section{Hepatic coma}

The EEG changes seen in patients showing various grades of hepatic coma are summarized in Table II. In the early phases of this investigation it became apparent that at certain stages of hepatic coma, the occurrence of an unusual kind of discharge became evident in the EEG. This discharge, which we have called the "triphasic wave," was at first mistaken for an eyeblink artifact, which it resembles very closely. However, it is not difficult to eliminate eyeblink artifact as a cause of these waves since blinking is relatively 

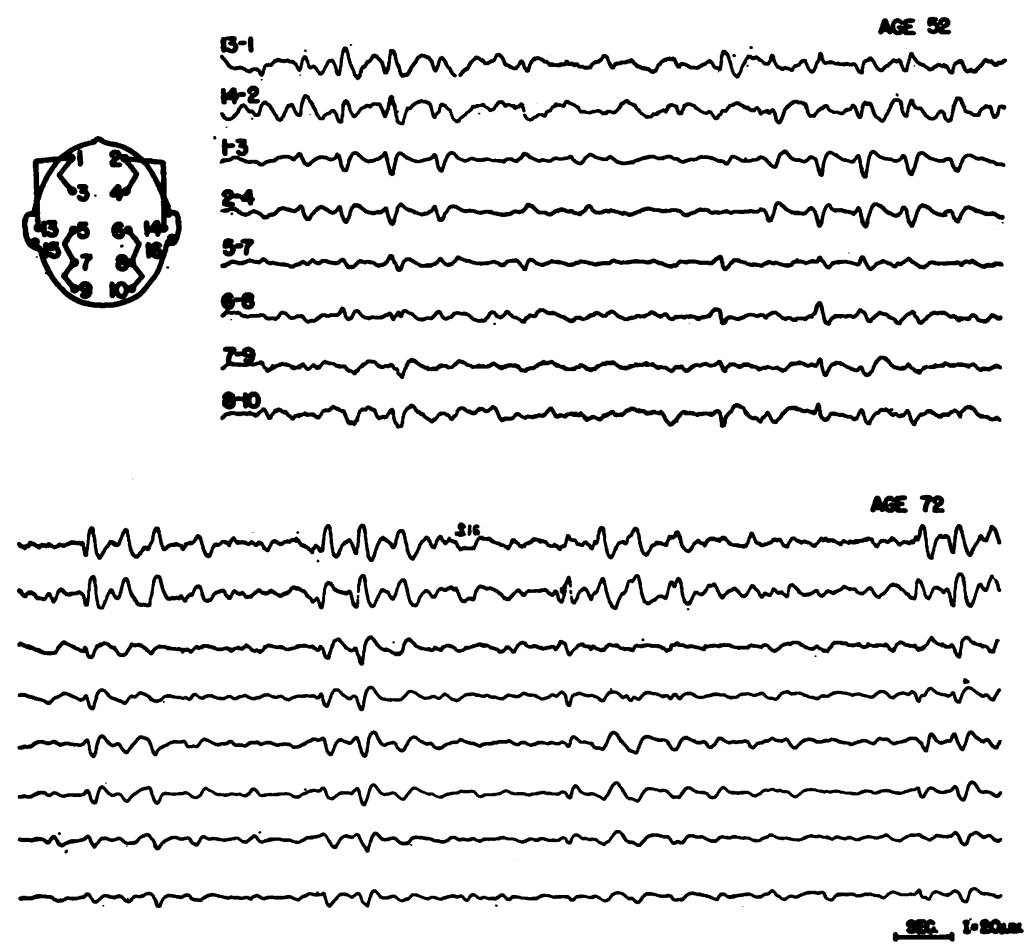

Fig. 1. EeG Changes in Hepatic Coma

Case 12, above, and case 13 , below, illustrate typical groups of triphasic waves with periods of relative quiescence.

TABLE I

Patients who had cirrhosis without mental change

\begin{tabular}{|c|c|c|c|c|c|c|}
\hline \multirow[b]{2}{*}{ Case } & \multirow[b]{2}{*}{$\underset{\text { years }}{\text { Age }}$} & \multirow[b]{2}{*}{ Clinical diagnosis } & \multicolumn{4}{|c|}{ EEG findinge* } \\
\hline & & & Alpha & Theta & $\begin{array}{c}\text { Tri- } \\
\text { phasic }\end{array}$ & Delta \\
\hline 1 & 41 & $\begin{array}{l}\text { Cirrhosis of liver, hemorrhage from } \\
\text { esophageal varices. Alcoholic }\end{array}$ & + & - & - & - \\
\hline 2 & 47 & $\begin{array}{l}\text { Portal cirrhosis of liver, ascites. } \\
\text { Alcoholic }\end{array}$ & ++ & - & - & - \\
\hline 3 & 41 & $\begin{array}{l}\text { Portal cirrhosis of liver. } \\
\text { Alcoholic }\end{array}$ & + & - & - & - \\
\hline 4 & 57 & $\begin{array}{l}\text { Portal cirrhosis of liver, ascites. } \\
\text { Alcoholic }\end{array}$ & + & - & - & - \\
\hline 5 & 49 & $\begin{array}{l}\text { Cirrhosis of liver, ascites. } \\
\text { Alcoholic }\end{array}$ & $+t+$ & - & - & - \\
\hline 6 & 55 & $\begin{array}{l}\text { Cirrhosis, ascites. Left } \\
\text { hydrothorax }\end{array}$ & ++ & - & - & - \\
\hline 7 & 35 & $\begin{array}{l}\text { Obstructive jaundice, biliary } \\
\text { cirrhosis }\end{array}$ & +++ & - & - & - \\
\hline 8 & 48 & Postnecrotic cirrhosis & + & - & - & - \\
\hline
\end{tabular}

- - indicates absence.

,,$+++++t$ indicate presence on a scale of 1 to 3 , depending on persistence of discharges. 
TABLE II

Patients with hepatic coma

\begin{tabular}{|c|c|c|c|c|c|c|c|c|}
\hline \multirow[b]{2}{*}{ Case } & \multirow[b]{2}{*}{$\begin{array}{c}\text { Age } \\
\text { years }\end{array}$} & \multirow[b]{2}{*}{ Clinical diagnosis } & \multirow[b]{2}{*}{ Mental status } & \multicolumn{4}{|c|}{ EEG findings* } & \multirow{2}{*}{$\begin{array}{c}\text { Survival } \\
\text { after } \\
\text { teot }\end{array}$} \\
\hline & & & & Alpha & Theta & $\begin{array}{c}\text { Tri- } \\
\text { phasic }\end{array}$ & Delta & \\
\hline 9 & 66 & $\begin{array}{l}\text { Cirrhosis of liver, ascites. } \\
\text { Alcoholic }\end{array}$ & Coma & - & - & $+t$ & - & 2 days \\
\hline 10 & 51 & $\begin{array}{l}\text { Cirrhosis of liver, eso- } \\
\text { phageal varices }\end{array}$ & $\begin{array}{l}\text { Alert-forgetful } \\
\text { (7-14-52) } \\
\text { Confused (7-25-52) }\end{array}$ & $\underline{-}$ & $\begin{array}{l}++ \\
+t\end{array}$ & $\bar{t}$ & $\overline{-}$ & 6 days \\
\hline 11 & 43 & $\begin{array}{l}\text { Cirrhosis of liver. G.I. } \\
\text { bleeding. Alcoholic }\end{array}$ & $\begin{array}{l}\text { Alert }(7-6-48) \\
\text { Semicoma }(7-19-48) \\
\text { Coma }(7-22-48)\end{array}$ & $\underline{ \pm}$ & $\begin{array}{l}+ \\
+ \\
+\end{array}$ & $\bar{t}$ & $\bar{z}$ & Few hours \\
\hline 12 & 52 & $\begin{array}{l}\text { Cirrhosis of liver, ascites. } \\
\text { Alcoholic }\end{array}$ & Coma & - & - & ++ & + & 2 days \\
\hline 13 & 72 & Cirrhosis of liver, ascites & $\begin{array}{l}\text { Semicoma }(6-27-52) \\
\text { Semicoma }(6-28-52) \\
\text { Coma }(6-30-52) \\
\text { Confused }(7-2-52)\end{array}$ & $\overline{\bar{z}}$ & $\bar{z}$ & $\begin{array}{l}++ \\
++ \\
+ \\
+\end{array}$ & $\bar{z}$ & $2 \frac{1}{2}$ months \\
\hline 14 & 64 & $\begin{array}{l}\text { Cirrhosis of liver: Cere- } \\
\text { bral degeneration } \\
\text { (Wilson's disease?). } \\
\text { Alcoholic }\end{array}$ & $\begin{array}{l}\text { Semicoma }(10-13-48) \\
\text { Semicoma }(10-19-48) \\
\text { Coma }(10-21-48) \\
\text { Confused }(10-22-48) \\
\text { Alert }(10-25-48) \\
\text { Alert }(10-26-48) \\
\text { Semicoma }(11-9-48) \\
\text { Confused }(3-4-49)\end{array}$ & $\begin{array}{l}\overline{-} \\
\overline{-} \\
\bar{t} \\
\overline{-}\end{array}$ & $\begin{array}{l}+ \\
+ \\
+ \\
+ \\
+ \\
+\end{array}$ & $\begin{array}{l}+ \\
+ \\
+ \\
+ \\
+ \\
+\end{array}$ & $\begin{array}{l}\bar{t} \\
\dot{+} \\
+ \\
+ \\
+\end{array}$ & 6 weeks \\
\hline 15 & 76 & $\begin{array}{l}\text { Biliary cirrhosis. Carci- } \\
\text { noma of pancreas caus- } \\
\text { ing obstruction of bile } \\
\text { duct }\end{array}$ & Coma & - & - & + & $+t$ & $1 \frac{1}{2}$ hours \\
\hline 16 & 33 & $\begin{array}{l}\text { Biliary cirrhosis second- } \\
\text { ary to common-duct } \\
\text { stricture }\end{array}$ & $\begin{array}{l}\text { Semicoma }(11-29-52) \\
\text { Alert }(12-2-52) \\
\text { Coma }(12-9-52)\end{array}$ & $\underline{\bar{t}}+$ & $\underline{+}$ & $\begin{array}{c}++ \\
- \\
\end{array}$ & $\bar{t}$ & 1 day \\
\hline 17 & 46 & $\begin{array}{l}\text { Biliary cirrhosis second- } \\
\text { ary to common-duct } \\
\text { stricture. Ascites }\end{array}$ & Coma & - & - & +++ & - & 5 days \\
\hline 18 & 42 & $\begin{array}{l}\text { Homologous serum hepa- } \\
\text { titis }\end{array}$ & $\begin{array}{l}\text { Coma }(4-20-49) \\
\text { Coma }(4-25-49) \\
\text { Semicoma }(4-26-49) \\
\text { Confused }(4-29-49)\end{array}$ & 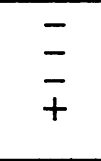 & $\begin{array}{l}+ \\
+ \\
+ \\
+\end{array}$ & $\begin{array}{c}+ \\
++ \\
+ \\
-\end{array}$ & $\frac{ \pm}{ \pm}$ & $\begin{array}{l}2 \text { days. No } \\
\text { EEG change } \\
\text { with } 2 \text { cc. } \\
\text { campolon } \\
\text { I.V. }\end{array}$ \\
\hline 19 & 63 & Infectious hepatitis & $\begin{array}{l}\text { Alert }(2-27-48) \\
\text { Alert }(3-1-48) \\
\text { Alert }(7-12-48) \\
\text { Coma }(8-17-48)\end{array}$ & $\begin{array}{l}+ \\
+ \\
+\end{array}$ & $\bar{z}$ & $\frac{-}{\overline{-}}+$ & $\begin{array}{l}+ \\
+ \\
+\end{array}$ & 2 days \\
\hline 20 & 17 & $\begin{array}{l}\text { Postnecrotic cirrhosis. } \\
\text { Chronic ulcerative } \\
\text { colitis }\end{array}$ & Coma & - & - & - & $++t$ & 12 hours \\
\hline 21 & 55 & $\begin{array}{l}\text { Metastatic carcinoma of } \\
\text { liver from breast }\end{array}$ & Coma & - & - & ++ & + & 5 days \\
\hline
\end{tabular}

* - indicates absence.

,,++++++ indicate presence on a scale of 1 to 3 , depending on persistence of discharges.

rare in comatose patients and the detailed properties of the waves, such as the fronto-occipital delay, could not be explained on the basis of eye movement. The properties of these waves will now be considered.

\section{Triphasic waves}

Two recordings illustrating the form and distribution of the triphasic waves are shown in Figure 1. In both instances triphasic waves are most clearly defined in the frontal and sylvian 
HEPATIC COMA : THE ELECTROENCEPHALOGRAPHIC PATTERN

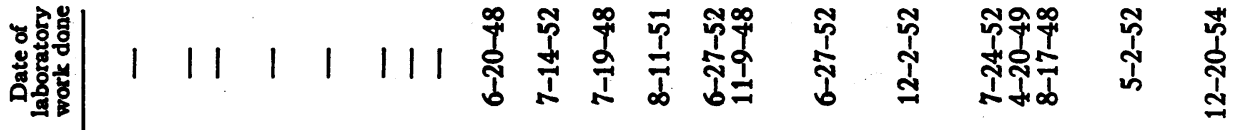

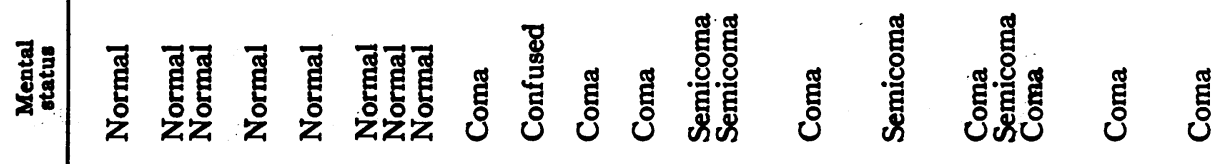

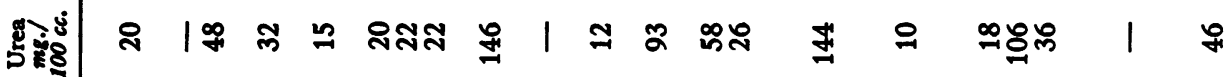

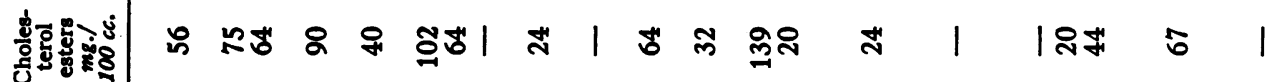

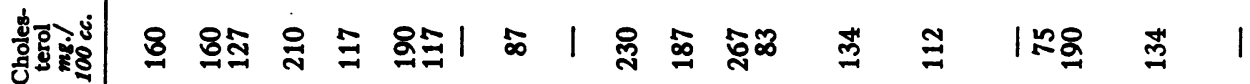

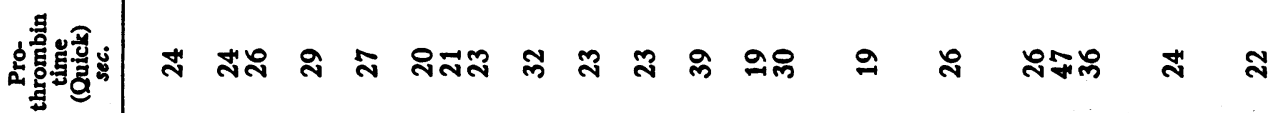

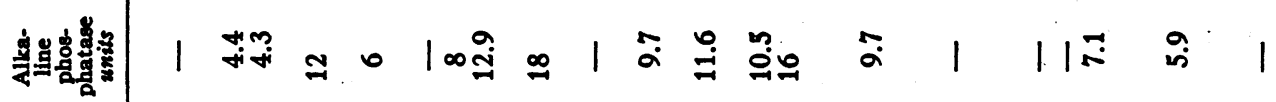

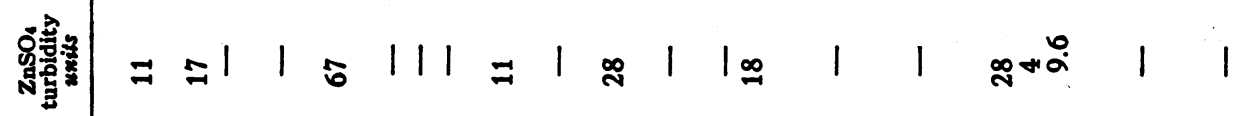
窇忽

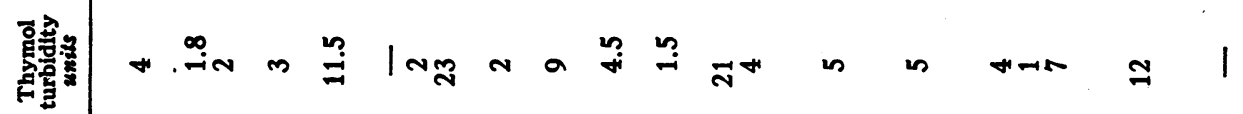

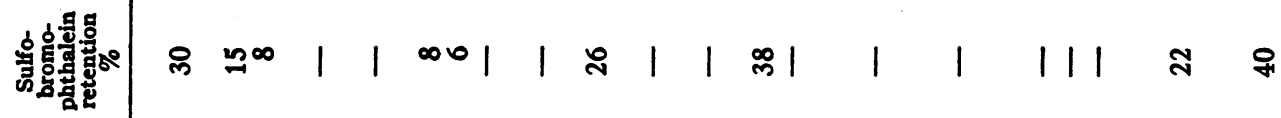

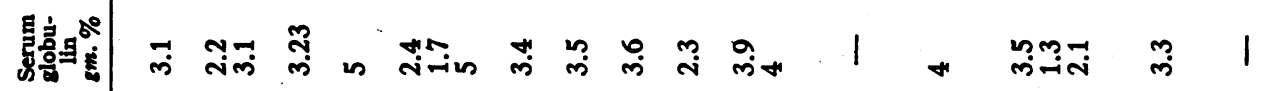

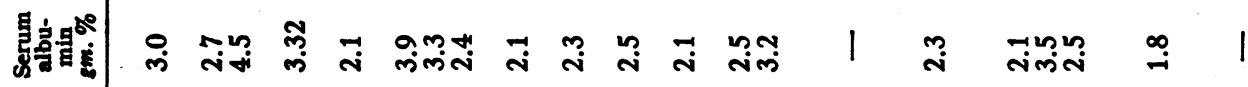

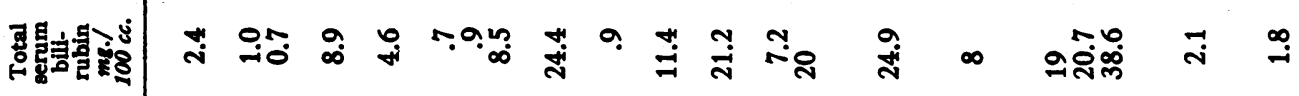

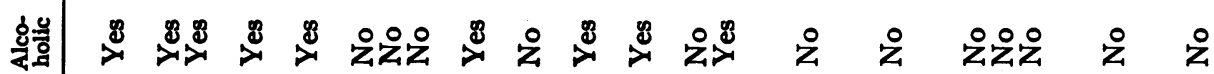

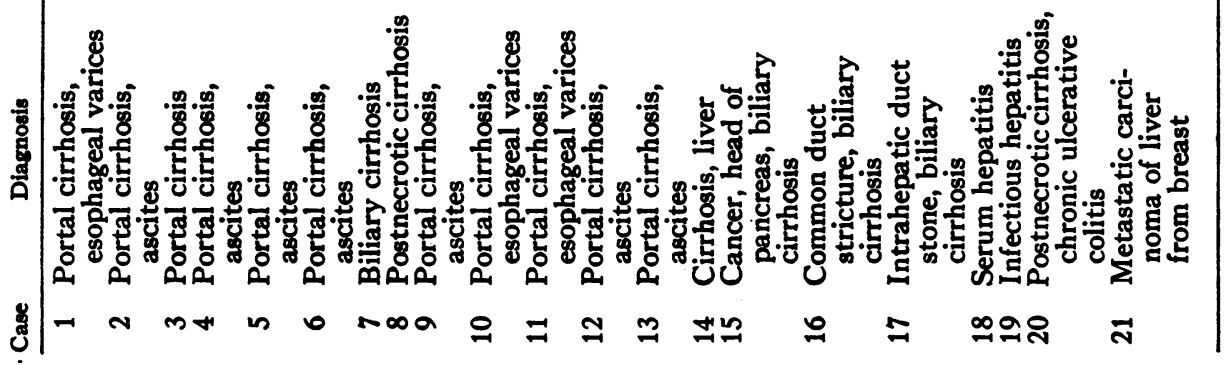




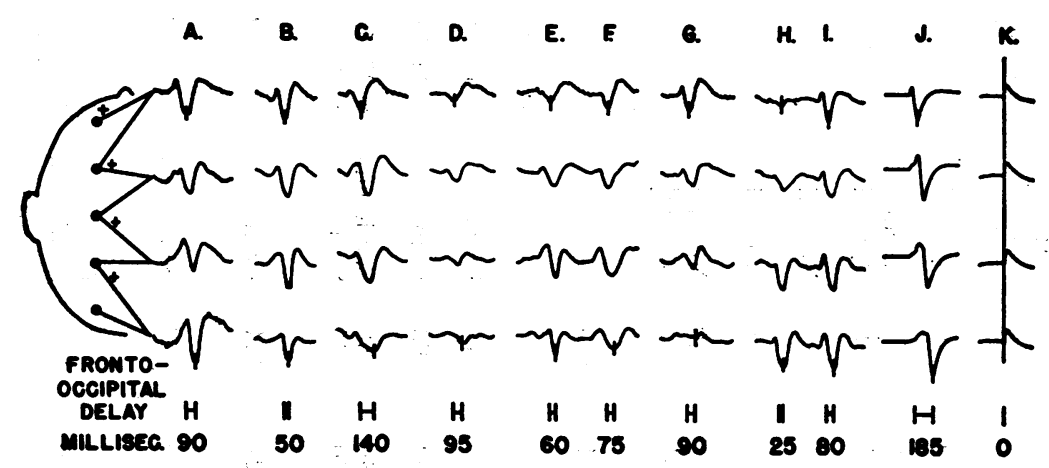

Fig. 2. Variabintry in Delay and Distribution of the Triphasic Waves

A, patient, 12 ; patient, case 13 ; J, synthetic waves from a model. In all cases the delays have been corrected for pen alignment and arc distortion of the trace.

areas, the amplitude falling to a relatively low value in the occipital region. The main deflection is downward, indicating a surface positive change. The main deflection is usually preceded and followed by low-amplitude negative deflections giving the whole complex a triphasic contour. The shape of the complex varies owing to changes in the relative prominence of the three waves.

There is a tendency for the occipital discharges to lag slightly in time in relation to the frontal discharges. This is well shown in Figure 2, in which the fronto-occipital delay has been measured for a series of waves belonging to various patients (A to I). The occipital regions show a delay varying from 25 to 140 milliseconds, following the peak of the main positive frontal discharge. These delays were not so clearly distinguishable in monopolar recordings. There is some variation in the contour of the discharge in different areas of the cortex and in a few instances (I) the amplitude is maximal in the occipital area. At other times the wave almost disappears before reaching the occi- pital area (G). Another variant is the wave which appears to arise in the sylvian regions and sweep posteriorly without involving the frontal regions appreciably. A tendency for the discharge to broaden as it migrates toward the occipital area is also frequently observed (F). The variability described above -is usually bilateral so that a high degree of symmetry between recordings from the two hemispheres is maintained. In addition to this there is usually bilateral synchrony of the triphasic waves within a few milliseconds.

The mechanism by which the triphasic waves are generated by the cortex is obscure, but evidence of delay in the peak of the discharge in the occipital areas, as compared with the frontal, naturally raises the question of a traveling wave of positivity sweeping the cortex from the frontal to the occipital regions. That such a moving electrical field will produce a deflection roughly comparable to the triphasic waves of the human being is shown in $\mathrm{J}$ (Figure 2), which is a recording from a model consisting of a saline bath in which

TABLE IV

EEG stages in hepatic coma

\begin{tabular}{|c|c|c|c|}
\hline & \multicolumn{3}{|c|}{ EEG pattern } \\
\hline & Theta $(4-7 \mathrm{c} / \mathrm{s})$ & Triphasic & Delta $(0.5-3 \mathrm{c} / \mathrm{s})$ \\
\hline Alpha & $\begin{array}{l}\text { Present but may be partly } \\
\text { disorganized }\end{array}$ & Usually absent & Absent \\
\hline $\begin{array}{l}\text { Mental } \\
\text { status }\end{array}$ & $\begin{array}{l}\text { Range from normal to mild } \\
\text { confusion with forgetful- } \\
\text { ness and irrational behavior }\end{array}$ & $\begin{array}{l}\text { Range from disorientation } \\
\text { and confusion to semi- } \\
\text { coma }\end{array}$ & $\begin{array}{l}\text { Semicoma to deep } \\
\text { coma }\end{array}$ \\
\hline Prognosis & May recover & May recover & Usually terminal \\
\hline
\end{tabular}




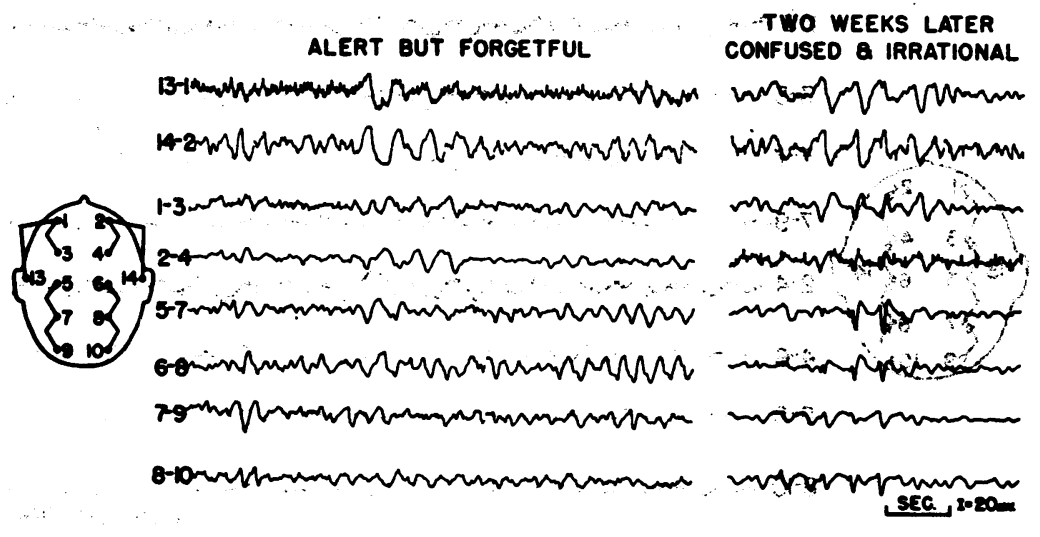

Fig. 3. Case 10: Theta Phase of Hepatrc Coura; wath Progression to Triphasic Phase Shown on the Right

a positive pole is swept past a series of electrodes representative of their position on the scalp. A conduction rate for this wave of about 1.5 meters per second would be required to give the observed delays, a value which is well within the observed conduction rates for the central tracts in animals.

A further possibility is that the primary disturb- ance is traveling at a subcortical (thalamic ?) level and that the changes in potential field observed on the cortical surface are merely the reflection of the primary disturbance (via thalamocortical relays) on to the cortical surface. The evidence at hand does not allow us to distinguish between these two hypotheses.

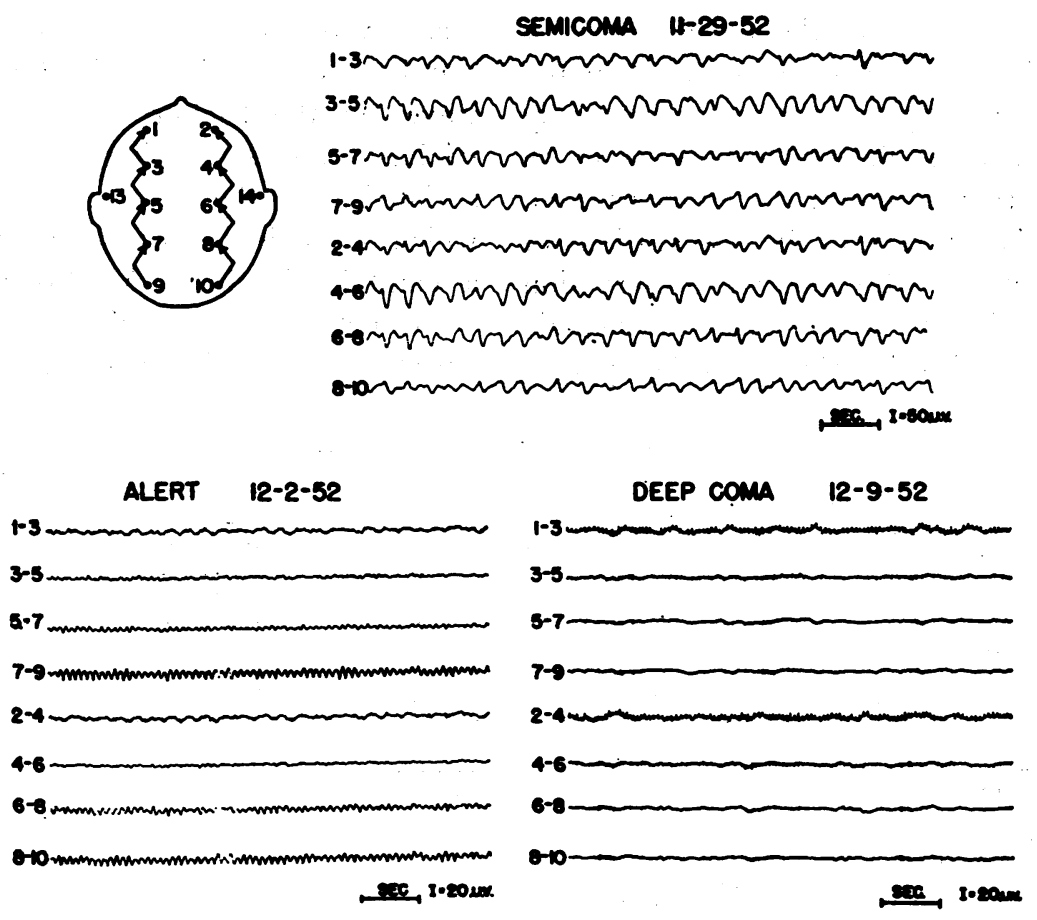

Fig. 4. Case 16: Changes in EEg Recordings from a Case or Hepatic Coxa

Triphasic waves are closely clustered in the recording on November 29 , 1952, though their presence is clearly evident in tracings from electrodes $1-3$ and $2-4$. 


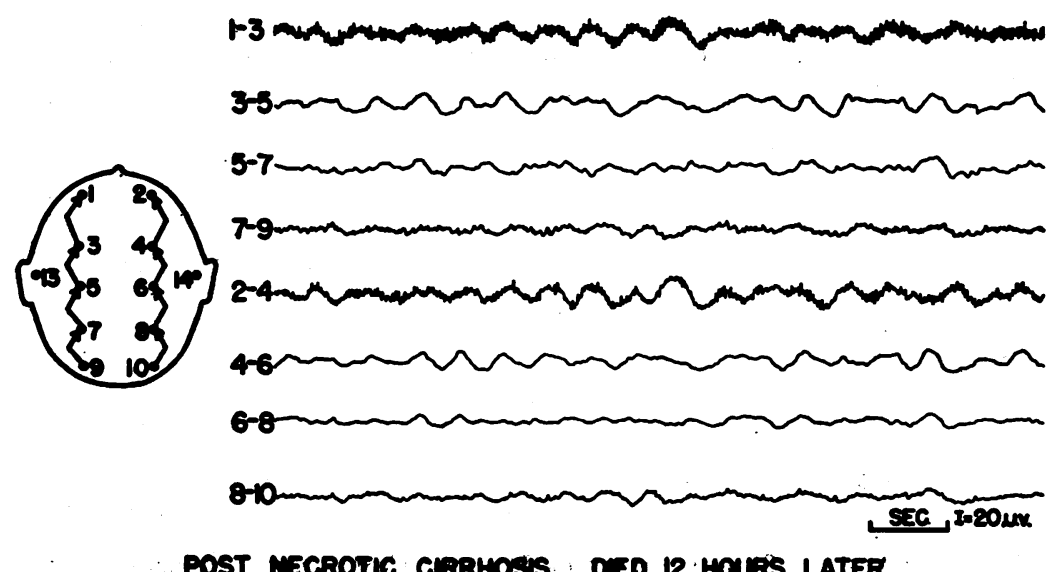

Fig. 5. Case 20: Slow Irregular Wáves of the Delta Stage in a Case of Postrecrotic Cirrhosis

The patient died 12 hours after the recording was made.

1. Occurrence of triphasic waves. While reference to Table II shows that triphasic waves were observed in all but one of the patients with disturbed consciousness, multiple recordings were frequently necessary to demonstrate their presence. A review of the findings indicates that they occur at a certain phase in the developrivent of hepatic coma. The first change indicated in the records of these patients at the time that early mental changes become detectable appears to be slowing and disorganization of the alpha rhythm, a finding which is contrary to the observations of Adams and Foley (2) who reported preservation of the alpha rhythm to a late stage of hepatic coma. Associated with this change is the appear- ance of waves of a frequency of 4 to 7 per second from all areas of the cortex. This may be called the "theta phase". (Table IV and Figure 3), and at this stage the patient is usually slightly disoriented with respect to time and place. With further deterioration in the clinical condition, triphasic waves make their appearance so that they can be recognized occasionally among the slow waves in the background. The appearance of triphasic waves (triphasic stage) is usually associated with the onset of a deeper coma from which the patient can be only partially aroused by a painful stimulus. At this time the triphasic waves may come to dominate the record to the exclusion of other frequencies. In some instances

CASE NO.

Fig. 6. Some Typical Tracings Showing Triphasic Waves in Hepatic Coma, with Recordings from a Patient Undergoing Ether Anesthesia and From a Patrent with a Convulsive Disorder for Couparison

These are bipolar recordings from frontomotor regions. 
the patient may make a rapid recovery from this stage with a return to normal pattern within a few hours (Figure 4). It should be noted how complete the EEG recovery can be without a vestige of abnormal activity remaining in the tracing. In the event of no recovery, the deepening coma is accompanied by the appearance of slower arrhythmic delta waves (Figure 5) followed by generalized suppression of activity (Figure 4). In our limited experience patients have not regained consciousness once the delta phase has been established for several days, which may, therefore, be regarded as having a grave prognosis.

2. Triphasic waves in other clinical conditions. The triphasic wave cannot be regarded as being entirely characteristic of the EEG in hepatic coma since its presence is confined to certain phases of the illness. In addition, somewhat similar discharges may be seen in such diverse conditions as ether anesthesia (Figure 6) and in rare instances in convulsive disorders. It has not been our experience that the discharge resembles the spike and wave of petit mal as suggested by Foley, Watson, and Adams (3) though there may be a fairly close resemblance to certain atypical bilaterally synchronous discharges which may be seen in the electroencephalogram of epileptic children. Cobb, Martin, and Pampiglione (4) have reported triphasic waves in cases of cerebral lipidosis but careful inspection of their tracings indicates that the polarity, duration, and distribution are different from those described here. A recent review of the EEG records of 345 patients with disturb-

TABLE $V$

Diagnostic categories of 345 patients with a mental state of confusion, semicoma or coma but without triphasic waves

(chronologic unselected group)

\begin{tabular}{lc}
\hline \hline \multicolumn{1}{c}{ Diagnosis } & Patient \\
\hline Cerebral tumor & 129 \\
Degenerative disease of brain & 50 \\
Cerebrovascular disease & 43 \\
Cerebral trauma & 27 \\
Encephalitis, meningitis & 20 \\
Subdural hematoma & 18 \\
Cerebral infarct & 18 \\
Psychosis & 12 \\
Organic psychosis & 9 \\
Convulsive disorder, postictal & 8 \\
Drug intoxication & 5 \\
Diabetes & 4 \\
Anoxic encephalopathy & 1 \\
Uremia & 1 \\
\hline
\end{tabular}

ances of consciousness (confusion, semicoma, coma) from varied causes, as shown in Table V, did not reveal the presence of any discharges that could be confused with the well-developed triphasic patterns seen in the patients with hepatic coma. Workers investigating the EEG in coma of nonhepatic origin have not reported the presence of triphasic waves (5). It may be concluded that the presence of triphasic waves in the record of a patient in coma may be taken as very suggestive evidence that the coma is hepatic in origin.

\section{Effect of sensory stimulation}

The effect of a painful arousal stimulus was determined in many patients in the various stages of hepatic coma. In the triphasic stage, the patient usually showed some response such as the withdrawal of a limb, but no consistent change in the EEG pattern during stimulation was observed. Likewise, photic stimulation was usually ineffective in producing a change in the triphasic pattern, and no response at the flash frequency used was seen in any case. The lack of response of the triphasic pattern to afferent stimulation is certainly in contrast to the responsiveness of abnormal patterns seen in some other varieties of coma, for example, postictal coma.

\section{Effect of liver extract on electroencephalogram}

In view of the possibility that these patients were suffering from some kind of deficiency of liver secretion, the effect of liver extract (campolon) on the electroencephalogram was observed in one patient (case 18). After a control tracing had been made, $2 \mathrm{cc}$. of campolon was given intravenously and the recording was continued for a further 90 minutes. No clinical or EEG change was noted.

\section{COMMENT}

While the EEG changes described cannot be regarded as indicating a specific pathologic state, they did give some clues to the likely mechanisms of the mental and neurologic symptoms of hepatic coma. The strict bilateral synchrony of the electrical discharges in the triphasic stage would suggest the participation of a diffuse synchronizing network, such as the thalamocortical reticular system. The rapid and complete reversibility 
of the EEG changes, at least in the triphasic stage, argues in favor of a chemical rather than a structural change in the region of the brain primarily involved. Furthermore, some chemical substances, such as ether, can produce electrical changes resembling those of hepatic coma.

The existence of some metabolic relationship between the liver and the brain has been suspected for more than a century. The demonstration by Geiger and Magnes (6) that a substance contained in the liver (or liver extract) is necessary for the persistence of electrical activity in the artificially perfused brain provided a physiologic basis for this relationship. More recently, Taylor (7) has attributed this survival-prolonging effect of liver extract upon EEG activity in the isolated brain preparation to its property of reducing permeability of the brain cell to glucose.

The data reported here seem to indicate that the particular kind of hepatic involvement (portal or biliary cirrhosis, or metastasis to the liver as in case 21) is unimportant so far as the tendency to produce characteristic EEG changes is concerned. This would suggest that the EEG changes result from some factor common to various types of hepatic pathology.

Independent evidence has recently been presented which suggests that various chemical substances are the responsible agents in the production of hepatic coma. Walshe (8) has reported an increased glutamine concentration in the cerebrospinal fluid of three patients who were in hepatic coma. More recently a number of workers have suggested that hepatic coma is related to metabolism of ammonia. Gabuzda, Phillips, and Davidson (9) described a syndrome indistinguishable from hepatic coma occurring in patients with cirrhosis given certain ammonia-containing cation exchange resins. The cause of the reaction was not apparent, but it was suggested that the effects were due to ammonia intoxication. The EEG alteration seen in one of their patients was said to simulate those described in hepatic coma: Later, Phillips, Schwartz, Gabuzda, and Davidson (10) demonstrated that apparently identical untoward effects can be provoked in patients with cirrhosis of the liver by administration of ammonium chloride, diammonium citrate, urea or dietary protein. The published illustration of the EEG tracings taken at the peak of the clinical reaction to these substances showed the nonspecific slow wave which may be seen in coma due to a number of different causes. No triphasic waves were recognizable in these tracings. Although increase in blood ammonia was suspected as being the cause of the reaction, the correlation between the concentration of blood ammonia and the abnormal signs observed was not consistent enough to establish a relation.

More recently, McDermott and Adams (11) have described a patient with an Eck fistula whose mental condition seemed to be related to the level of blood ammonia, and who presented episodes of stupor when the intake of substances related to ammonia metabolism was changed artificially. The described changes in the EEG again appear to be nonspecific, and in the absence of published tracings it is impossible to be certain whether or not triphasic waves were present at any stage.

It is evident that an increasing difficulty in these cases is that of relating induced "hepatic-comalike" syndromes now encountered in both clinical and animal work with the genuine clinical hepaticcoma syndrome. Electroencephalographic data should contribute useful evidence in establishing these relationships in addition to their diagnostic and perhaps prognostic value in individual patients.

\section{SUMMARY}

In the electroencephalograms of 12 patients in various stages of hepatic coma the following stages have been recognized as the depth of coma increased: 1) theta stage, with diffuse waves of a frequency of 4 to 7 per second, 2) triphasic stage characterized by diffuse bilaterally synchronous triphasic waves whose maximal deflection is surface positive, and 3) delta stage in which random arrhythmic waves with little bilateral synchrony dominate the record. A control group of 8 patients who had hepatic cirrhosis and impairment of hepatic function, as measured by laboratory means, that were essentially as great as that of the 13 patients, but who had no mental change, showed EEG recordings that were within normal limits.

Patients in the theta stage are usually moderately confused, while those in the triphasic and delta stages are usually semicomatose or completely unresponsive. 
Some evidence from latency measurements suggests that the triphasic wave is a conducted disturbance. Waves somewhat similar to the triphasic discharges have been seen in other conditions such as ether anesthesia and convulsive disorders but not in patients in coma from other causes.

It is suggested that in addition to being clinically useful from the diagnostic and perhaps prognostic points of view, the EEG may assist in relating experimental coma syridromes to genuine hepatic coma.

\section{REFERENCES}

1. Magoun, $H . W$. The ascending reticular activating system. A. Research Nerv. \& Ment. Dis., Proc., $1952,30,480$.

2. Adams, R. D., and Foley, J. M., The neurological disorder associated : with liver disease. A. Research Nerv. \& Ment. Dis., Proc., 1953, 32, 198.

3. Foley, J. M., Watson, C. W., and Adams, R. D., Significance of the electroencephalographic changes in hepatic coma. Tr. Am. Neurol. A., 1950, 75, 161.

4. Cobb, W., Martin, F., and Pampiglione, G., Cerebral lipidosis: An electroencephalographic study. Brain, 1952, 75, 343.
5. Li, C.-L., Jasper, H., and Henderson, L., Jr., The effect of arousal mechanisms on various forms of abnormality in the electroencephalogram. Electroencephalog. \& Clin. Neurophysiol, 1952, 4, 513.

6. Geiger, A., and Magnes, J., The isolation of the cerebral circulation and the perfusion of the brain in the living cat. Am. J. Physiol., 1947, 149, 517.

7. Taylor, R. M., Technic for perfusion of the completely isolated brain in the living cat in Milbank Memorial Fund, 27th Annual Conference: The Biology of Mental Health and Disease, New York, Paul B. Hoeber, Inc., 1952, pp. 48-53.

8. Walshe, J. M., Observations on the symptomatology and pathogenesis of hepatic coma. Quart. J. Med., 1951, ni.s. $20,421$.

9. Gabuzda, G. J., Jr., Phillips, G. B., and Davidson, C. S., Reversible toxic manifestations in patients with cirrhosis of the liver given cation-exchange resins. New England J. Med, 1952, 246, 124. :

10. Phillips, G. B., Schwartz, R., Gabuzda, G. J., Jr, and Davidson, C, S., The syndrome of impending hepatic coma in patients with cirrhosis of the liver given certain nitrogenous substances. New England J. Med., 1952, 247, 239.

11. McDermott, W. V., Jr., and Adams, R. D., Episodic stupor associated with an Eck fistula in the human with particular reference to the metabolism of ammonia. J. Clin. Invest., 1954, 33; 1. 